\title{
KARAKTERISTIK FAKTOR RISIKO KELAHIRAN PREMATUR DI RUMAH SAKIT UMUM YK MADIRA PALEMBANG
}

\section{CHARACTERISTICS RISK FACTORS OF PREMATURE BIRTH IN YK MADIRA PUBLIC HOSPITAL, PALEMBANG}

\author{
${ }^{1}$ Rika Ariana, ${ }^{2}$ Fika Minata Wathan \\ ${ }^{1}$ Diploma IV Kebidanan, Universitas Kader Bangsa Palembang \\ ${ }^{2}$ Program Doktoral Kesehatan Masyarakat, Universitas Indonesia \\ Korespondensi: rika.ariana8509@gmail.com
}

\begin{abstract}
The One of Sustainable Development Goals (SDGs) in goals 3.2 were reducing Neonatal Mortality Rate to 12/1,000 live births. Preterm birth contributed greatly to neonatal morbidity and mortality. Based on the results of a review medical records of the YK Madira Hospital in Palembang showed an increase the prevalence of preterm birth in 2018 to $5.7 \%$ and in 2019 an increased of 8.0\%. The research aims to determine the correlation between risk factors for preterm birth. This research was an analytical survey, cross-sectional design using secondary with a systematic random sampling period Januari-Desember 2019 totaling 202 samples. Data analysis was performed using chi-square test for bivariate, logistic regression for multivariate, the results showed that there was a significant correlation between age ( $p$-value $=0.000$ $O R=3.4 ; 95 \%$ CI: 1.82-6, 39), education ( $p$-value $=0.009$ OR $=2.4 ; 95 \%$ CI: 1.28 4.58), history of preterm birth ( $p$-value $=0.008$ OR $=2.7 ; 95 \%$ CI: 1, 35-5.54), ANC examination ( $p$-value $=0.031$ OR $=2.5 ; 95 \% C I$ : 1.15-5.72) smoking variable obtain $p$ value $=1,000(p>0.05)$. Conclusion: The most dominant factor in occurrence of preterm birth were age and history of preterm birth. These results could be used as a based for information by health practitioners can further improve counselling and education for women with risky age and also to improved antenatal care as a promotive, preventive action of premature birth to support the achievement of government program targets in reducing the neonatal mortality rate in Indonesia.
\end{abstract}

Keywords : premature birth, Education, ANC, History of preterm birth, Age

\begin{abstract}
ABSTRAK
Tujuan pembangunan berkelanjutan pada goals ke 3.2 salah satunya menurunkan Angka Kematian Neonatal 12/1.000 kelahiran hidup. Kelahiran prematur berkontribusi besar dalam morbiditas dan mortalitas masa neonatal. Berdasarkan hasil riview rekam medis RSU YK Madira Palembang menunjukan peningkatan prevalensi kelahiran prematur tahun 2018 sebesar 5,7\% dan di tahun 2019 meningkat 8,0\%. Tujuan penelitian untuk mengetahui hubungan antara faktor risiko terhadap kelahiran prematur. Penelitian ini bersifat survey analitik, desain cross-sectional menggunakan data sekunder rekam medis periode Januari-Desember 2019 dengan teknik systhematic random sampling berjumlah 202 sampel. Analisis data dilakukan uji chi-square untuk bivariate, regresi logistic untuk multivariate. Hasil penelitian menunjukan ada hubungan bermakna antara usia ( $p$-value $=0,000 \mathrm{OR}=3,4 ; 95 \% \mathrm{CI}$ : 1,82-6,39), pendidikan $(p$-value $=0,009 \mathrm{OR}=2,4$;
\end{abstract}


95\% CI : 1,28-4,58), riwayat kelahiran prematur ( $p$-value $=0,008$ OR=2,7; 95\% CI : $1,35-5,54)$, pemeriksaan ANC ( $p$-value $=0,031$ OR=2,5; 95\% CI : 1,15-5,72) dengan kejadian kelahiran prematur, variabel merokok didapatkan $p$-value $=1,000$. Kesimpulan : Variabel yang paling dominan mempengaruhi kelahiran prematur yaitu usia dan riwayat kelahiran prematur. Penelitian ini dapat dijadikan dasar informasi agar tenaga kesehatan meningkatkan KIE pada ibu yang berusia resiko tinggi serta meningkatkan pelayanan kunjungan Antenatal care (ANC) sesuai program pemerintah sebagai tindakan promotif dan preventif mencegah kelahiran prematur guna mendukung pencapaian target program pemerintah dalam menurunkan angka kematian neonatal di Indonesia.

\section{Kata Kunci : Kelahiran Prematur, Pendidikan, ANC, Riwayat kelahiran prematur, Usia}

\section{PENDAHULUAN}

Kelahiran prematur adalah kelahiran sebelum usia kehamilan 37 minggu atau kurang dari 259 hari dari tanggal pertama periode menstruasi terakhir seorang wanita. Secara global estimasi angka kelahiran prematur dunia sebesar 9,8\% pada tahun 2000 dan meningkat 10,6\% pada tahun 2014 (Saifon Chawanpaiboon*, 2019). Data World Health Organization (WHO) menunjukan peringkat kelahiran prematur semua negara didunia dengan jumlah kelahiran prematur tertinggi yaitu India sebesar 3.519.100, China 1.172.300, Nigeria 773.600, Pakistan 748.100 dan Indonesia berada pada peringkat 5 dengan jumlah kelahiran prematur sebesar 675.700, di ikuti negara Amerika sebesar 517.400, Bangladesh 424.100, Philipines 348.900, Republik Demokratik Congo
341.400 dan Brazil 279.300 (Blencowe et al., 2013).

Komplikasi kelahiran prematur adalah penyebab utama kematian pada anak-anak di bawah usia 5 tahun sekitar $16 \%$ dari semua kematian, dan $35 \%$ kematian pada bayi baru lahir (Saifon Chawanpaiboon*, 2019). Bayi yang lahir prematur memiliki resiko kematian yang lebih tinggi, resiko penyakit, disabilitas dalam hal motorik jangka panjang, kognitif visual, pendengaran, sikap, emosi, kesehatan dan masalah pertumbuhan jika dibandingkan dengan bayi normal (Zhang et al., 2012). Risiko kematian pada bayi prematur terutama dengan usia kehamilan $<32$ minggu sebesar 70 kali lebih tinggi (Halimah Rosyidah1, 2019).

Di Indonesia berdasarkan hasil Survei Demografi Kesehatan Indonesia (SDKI) menunjukan bahwa Angka Kematian Neonatal (AKN) mengalami 
penurunan akan tetapi masih jauh dari target RENSTRA dan RPJMN 20202024 yaitu menargetkan Angka Kematian Neonatal (AKN) sebesar 12,9/1.000 KH. Hasil Survey Demografi kesehatan Indonesia (SDKI) 2002 meunjukan Angka kematian neonatal (AKN) sebesar 20/1.000 KH, SDKI 2007 sebesar 19/1.000 KH dan tahun 2012 stagnan sebesar 19/1.000 KH dan hasil SDKI tahun 2017 Angka Kematian Neonatal (AKN) sebesar 15 per 1.000 kelahiran hidup.

,Berdasarkan data Laporan Kinerja Program (LAKIP) kesga Dinas Kesehatan Provinsi Sumatera Selatan menunjukan kematian bayi di provinsi Sumatera Selatan pada tahun 2019 mengalami peningkatan yaitu sebesar 508 kasus kematian bayi, dimana pada tahun 2018 sebesar 497 kasus. dengan prevalensi kematian neonatal sebesar $83,1 \%$ dan $16,9 \%$ kematian masa post neonatal. Penyebab kematian neonatal tertinggi adalah bayi lahir dengan Berat Badan Lahir Rendah (BBLR)/Prematur sebesar $48 \%$ dan asfiksia $36 \%$.

Berbagai upaya pemerintah dalam menurunkan angka kematian bayi/ neonatal salah satunya melalui program Indonesia sehat dengan pendekatan keluarga (PIS-PK) melalui
Peraturan Menteri Kesehatan No. 39 Tahun 2016. Berdasarkan indikator Rencana Pembangunan Jangka Menengah Nasional (RPJMN) dan Rencana Strategis (Renstra) tahun 20202024, Salah satu hal yang harus dilakukan untuk mencegah kematian bayi baru lahir khusus yang berkaitan dengan kelahiran prematur yaitu meningkatkan intervensi klinis prioritas kelangsungan hidup ibu dan neonatus dengan Pemberian Antenatal Corticoseroid (ACS) pada ibu dengan risiko bayi prematur, Perawatan khusus untuk bayi prematur / BBLR( berat badan lahir rendah) termasuk perawatan metode kangguru (PMK), Pelayanan neonatal essensial (termasuk inisiasi menyusu dini (IMD)/ pemberian ASI ekslusif, Resusitasi neonatal yang mengalami asfiksia dan deteksi dini serta penanganan sepsis pada masa neonatal (Kesmas, 2020).

Kelahiran prematur merupakan kelainan proses yang multifaktor, faktor maternal yang berpengaruh pada kejadian kelahiran prematur adalah faktor usia, status gizi, paritas, penyakit maternal dan faktor dari gaya hidup ibu seperti merokok dan minum alkohol (Manuaba IBG, 2012). Adanya peningkatan prevalensi kelahiran prematur di rumah 
sakit umum YK Madira Palembang tahun 2018 sebesar $5,7 \quad \%$ dan meningkat ditahun 2019 sebesar 8,0\% dari 899 kelahiran. Tujuan penelitian ini untuk menganalisis hubungan faktor risiko terhadap kelahiran prematur di rumah sakit umum YK Madira Palembang.

\section{METODE}

Desain dalam penelitian ini bersifat kuantitatif dengan metode survey analitik, pendekatan cross sectional. Populasi dalam penelitian ini adalah semua ibu bersalin di rumah sakit umum YK Madira Palembang pada tahun 2019 berjumlah 899 kelahiran. Sampel dihitung menggunakan rumus Lameshow berjumlah 202 orang, diambil secara random dengan teknik systhematic random sampling. Analisis data dilakukan secara statistic dengan uji chi-square untuk bivariate dengan SPSS versi 20 dan regresi logistic untuk multivariate analisis. Penelitian ini telah memperoleh surat izin dari kepala bagian pendidikan dan pelatihan RSU YK Madira dengan Nomor: 00163/RSU_YKM/VII/2020.

\section{HASIL DAN PEMBAHASAN}

Penelitian ini dilakukan pada semua data rekam medis ibu yang melahirkan tahun 2019 di rumah sakit umum YK Madira Palembang berjumlah 202 orang. Hasil analisis univariate menunjukan ada $72(35,6 \%)$ responden dengan kelahiran prematur dan 130 $(64,4 \%)$ responden yang melahirkan tidak prematur. Dapat dilihat juga distribusi karakteristik berbagai faktor resiko pada kelahiran prematur di RSU YK Madira Palembang, dijelaskan pada tabel berikut:

Tabel 1. Distribusi frekuensi kelahiran prematur di RSU YK Madira Palembang

\begin{tabular}{ccc}
\hline $\begin{array}{c}\text { Kelahiran } \\
\text { Prematur }\end{array}$ & $\begin{array}{c}\text { Frekuensi } \\
(\mathbf{n})\end{array}$ & $\begin{array}{c}\text { Persentase } \\
(\boldsymbol{\%})\end{array}$ \\
\hline Ya & 72 & 35,6 \\
Tidak & 130 & 64,4 \\
\hline Total & 202 & 100 \\
\hline
\end{tabular}

Sumber : Data Sekunder, 2019

Tabel 2. Distribusi Karakteristik (Faktor Risiko) Responden kelahiran Prematur di RSU YK Madira Palembang

\begin{tabular}{|c|c|c|}
\hline $\begin{array}{c}\text { Karakteristik } \\
\text { Responden }\end{array}$ & $\begin{array}{l}\text { Frekuensi } \\
\text { (n) }\end{array}$ & $\begin{array}{c}\text { Persentase } \\
(\%)\end{array}$ \\
\hline \multicolumn{3}{|l|}{ Usia } \\
\hline \multicolumn{3}{|l|}{$\overline{\text { Berisiko }}$} \\
\hline $\begin{array}{l}\text { Tidak Berisiko } \\
\text { (20-35 tahun) }\end{array}$ & 141 & 69,8 \\
\hline \multicolumn{3}{|l|}{ Pendidikan } \\
\hline Rendah & 55 & 27,2 \\
\hline Tinggi & 147 & 72,8 \\
\hline \multicolumn{3}{|l|}{ Riwayat } \\
\hline \multicolumn{3}{|l|}{ Kelahiran } \\
\hline \multicolumn{3}{|l|}{ Prematur } \\
\hline$\overline{\mathrm{Ya}}$ & 40 & 19,8 \\
\hline Tidak & 162 & 8 \\
\hline \multicolumn{3}{|l|}{ Merokok } \\
\hline$\overline{\mathrm{Ya}}$ & 6 & 3,0 \\
\hline Tidak & 196 & 97,0 \\
\hline \multicolumn{3}{|l|}{ Pemeriksaan } \\
\hline \multicolumn{3}{|l|}{ ANC } \\
\hline$\overline{\mathrm{Ya}}$ & 29 & 14,4 \\
\hline Tidak & 173 & 85,6 \\
\hline
\end{tabular}


Hasil analisis bivariate menunjukan adanya hubungan yang bermakna ( $\mathrm{p}$-value $<0,05$ ) antara variabel faktor resiko dengan kelahiran prematur, dijelaskan dengan tabel sebagai berikut:

Tabel 3. Hasil Analisis Hubungan Faktor Risiko dengan kelahiran prematur di Rumah Sakit Umum YK Madira Palembang

\begin{tabular}{|c|c|c|c|c|c|c|}
\hline \multirow{3}{*}{$\underline{\text { Faktor Risiko }}$} & \multicolumn{4}{|c|}{ Prematur } & \multirow{3}{*}{$\begin{array}{c}\text { OR } \\
(95 \% \mathrm{CI})\end{array}$} & \multirow{3}{*}{$P$-Value } \\
\hline & \multicolumn{2}{|c|}{ Ya } & \multicolumn{2}{|c|}{ Tidak } & & \\
\hline & n & $\%$ & $\mathbf{N}$ & $\%$ & & \\
\hline \multirow{3}{*}{$\begin{array}{l}\text { Usia } \\
\text { Berisiko Tinggi } \\
(<20 />35 \text { tahun }) \\
\text { Tidak Berisiko } \\
\text { (20-35 tahun) }\end{array}$} & & & & & \multirow{3}{*}{$\begin{array}{c}3,4 \\
(1,82-6,39)\end{array}$} & \multirow{3}{*}{0,000} \\
\hline & 34 & 47,2 & 27 & 20,8 & & \\
\hline & 38 & 52,8 & 103 & 79,2 & & \\
\hline \multicolumn{6}{|l|}{ Pendidikan } & \multirow{3}{*}{0,009} \\
\hline Rendah & 28 & 38,9 & 27 & 20,8 & 2,4 & \\
\hline Tinggi & 44 & 61,1 & 103 & 79,2 & $(1,28-4,58)$ & \\
\hline \multicolumn{7}{|l|}{ Riwayat } \\
\hline \multicolumn{7}{|l|}{ Kelahiran } \\
\hline \multicolumn{7}{|l|}{ Prematur } \\
\hline Ya & 22 & 30,6 & 18 & 13,8 & 2,7 & \multirow{2}{*}{0,008} \\
\hline Tidak & 50 & 69,4 & 112 & 86,2 & $(1,35-5,54)$ & \\
\hline \multicolumn{7}{|l|}{ Merokok } \\
\hline$\overline{Y a}$ & 2 & 2,8 & 4 & 3,1 & 0,9 & \multirow[t]{2}{*}{1,000} \\
\hline Tidak & 70 & 97,2 & 126 & 96,9 & $(0,16-5,03)$ & \\
\hline \multicolumn{6}{|l|}{ Pemeriksaan } & \multirow{4}{*}{0,031} \\
\hline$\underline{\mathrm{ANC}}$ & & & & & & \\
\hline $\mathrm{Ya}$ & 16 & 22,2 & 13 & 10 & 2,5 & \\
\hline Tidak & 56 & 77,8 & 117 & 90 & $(1,15-5,7)$ & \\
\hline
\end{tabular}

Tabel 4 Hasil Analisis Multivariat Regresi Logistik dengan 4 variabel kandidat Model multivariat

\begin{tabular}{lllll}
\hline \multirow{2}{*}{ Variabel } & OR & \multicolumn{2}{c}{$95,0 \%$ C.1.for } & P \\
\cline { 3 - 4 } & & \multicolumn{2}{c}{ EXP(B) } & Value \\
\cline { 3 - 4 } & 2,8 & 1,44 & 5,45 & 0,002 \\
\hline Usia & & & & \\
\hline $\begin{array}{l}\text { Riwayat } \\
\text { Kelahiran }\end{array}$ & & & & \\
Prematur & 1,8 & 0,71 & 4,77 & 0,203 \\
\hline Pendidikan & 2,2 & 1,14 & 4,45 & 0,018 \\
\hline $\begin{array}{l}\text { Pemeriksaa } \\
\text { n Antenatal }\end{array}$ & & & & \\
Care (ANC) & 1,7 & 0,65 & 5,17 & 0,291 \\
\hline
\end{tabular}

Berdasarkan hasil multivariate analisis regresi logistic dengan melakukan permodelan, yang menampilkan nilai Odds Ratio (OR) dan Confidence Interval (CI) 95\% maka variabel yang masuk permodelan yaitu usia, pendidikan, riwayat kelahiran prematur dan pemeriksaan antenatal care (ANC) selanjutnya dianalisis secara multivariat maka variabel yang mempunyai nilai $p$ $>0,25$ satu persatu di eliminasi dari 
model dengan variable backward stepwise selection (analisa regresi logistic dengan cara seleksi mundur) sampai didapatkan fit model akhir analisis dan dapat dilihat seberapa jauh peluang seluruh variabel dalam setiap model memprediksi proporsi kelahiran prematur.

Tabel 5. Hasil Uji interaksi antara variabel yang berinteraksi dengan kelahiran premature

$95.0 \%$

C.I.for

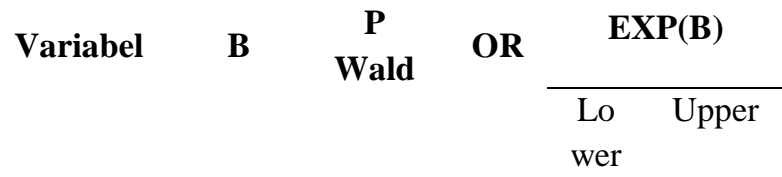

\begin{tabular}{llllll}
\hline $\begin{array}{l}\text { Riwayat } \\
\text { kelahiran } \\
\text { prematur }\end{array}$ & 0,54 & 16,075 & 1,71 & 1,31 & 2,2 \\
by Usia & & & & & \\
\end{tabular}

\begin{tabular}{llllll}
\hline Constant & $-1,03$ & 5,9 & 0,35 & - & -
\end{tabular}

-2 Log-Likelihood $=246,32 \mathrm{G}=16,8 \mathrm{p}$ value : 0,000

Hasil dari tabel 5 menunjukan proses analisa yang telah dilakukan untuk uji interaksi maka dapat di simpulkan bahwa variabel usia dengan riwayat kelahiran premature $(p$-value $=0,000)$ secara bersama-sama (simultan) mempengaruhi kejadian kelahiran prematur di Rumah Sakit Umum YK Madira Palembang tahun 2019.

\section{Hasil uji Chi-square} menunjukan nilai $p$-value $=0,000, \mathrm{OR}$ $=3,4 \quad(95 \%$ CI: $(1,82-6,39))$ artinya secara statistik terdapat hubungan yang bermakna antara usia ibu $(<20$ atau $>35$ tahun) dengan kelahiran prematur dan ibu berusia risiko berpeluang 3,4 kali lebih tinggi untuk mengalami kelahiran prematur jika dibandingkan ibu yang berusia 20-35 tahun. Pada kehamilan dengan usia ibu terlalu muda $(<20$ tahun) secara fisik dan psikis masih kurang, misalnya perhatian dalam pemenuhan nutrisi zat-zat gizi selama kehamilannya, sedangkan pada usia ibu $>35$ tahun berkaitan dengan kemunduran dan penurunan daya tahan tubuh serta berbagai penyakit sering menimpa pada usia ini (Widyastuti, 2010). Hasil penelitian ini sejalan dengan penelitian (Syarif et al., 2017) yang menunjukan adanya hubungan yang bermakna antara usia ibu dengan kelahiran prematur dengan $p$ value $=0,002$ dengan tingkat keeratan sebesar 0,227 (rendah). Penelitian ini juga sejalan dengan hasil penelitian yang dilakukan oleh (Halimah Rosyidah1, 2019) yang menyatakan ada hubungan yang bermakna antara usia dengan kelahiran prematur dengan nilai koefisen korelasi sebesar 0,192 dan nilai sig 0,046 ( $\mathrm{p}<0,05)$, sejalan juga dengan hasil analsis statistik yang dilakukan oleh (Wahyuni R, 2017) yaitu terdapat 
hubungan yang bermakna antara usia ibu dengan kelahiran prematur dengan $p$-value $=0,017$ dan OR sebesar 2,95(95\% CI: 1,278-6,810). Sejalan juga dengan penelitian (Marisa Ip, 2010) dengan hasil pada ibu usia muda $<20$ tahun didapatkan sebesar $\mathrm{OR}=2.07$ (95\% CI: 1.19- 3,61), usia >35 tahun $\mathrm{OR}=2.27(95 \%$, CI: 1.40, 3.68). Peneliti berasumsi sesuai dengan teori yang ada bahwa kecenderungan kasus terjadinya kelahiran prematur pada usia terlalu muda yaitu $<20$ tahun berkaitan dengan organ reproduksi yang belum matang secara penuh maka sangat dianjurkan untuk menikah pada usia yang matang, sangat dianjurkan untuk meningkatkan konseling kesehatan reproduksi pada calon pengantin dan juga pada ibu hamil dengan kelompok resiko tinggi. sedangkan usia ibu >35 tahun dikaitkan dengan kesehatan yang berkurang, fungsi rahim menurun dan kualitas yang menurun.

Pendidikan merupakan sesuatu yang dapat membawa seseorang untuk memiliki ataupun meraih wawasan dan pengetahuan yang lebih luas jika dibandingkan dengan orang yang berpendidikan yang lebih rendah. Pada variabel pendidikan secara statistic didapatkan adanya hubungan yang signifikan dengan $p$-value $=0,009$ dan OR sebesar 2,4 (95\% CI: 1,28-4,58) yang artinya ibu hamil yang berpendidikan rendah berisiko 2,4 kali lebih tinggi untuk mengalami kelahiran prematur. Penelitian ini sejalan dengan hasil penelitian (Do Carmo Leal et al., 2016) bahwa faktor penyebab kelahiran prematur spontan berkaitan dengan aspek sosiodemografik salah satunya adalah tingkat pendidikan yang rendah. Hal ini sejalan juga dengan penelitian (Sulistiarini \& Berliana, 2016) bahwa wanita yang berpendidikan rendah cenderung 1,077 kali lebih besar mengalami kelahiran prematur dibandingkan ibu berpendidikan tinggi. (El-Sayed \& Galea, 2012) menyatakan bahwa kejadian kelahiran prematur meningkat pada ibu berpendidikan rendah $<12$ tahun lebih berisiko 1,73 kali bila dibandingkan ibu berpendidikan diploma atau derajat yang lebih tinggi. Peneliti berasumsi bahwa semakin tinggi pendidikan ibu maka akan semakin mudah menerima informasi dan semakin banyak ilmu pengetahuan yang diterima oleh ibu hamil tersebut sehingga kemampuan nya dalam berpikir akan lebih rasional termasuk tentang menjaga kesehatan, pencegahan terjadinya kelahiran 
prematur serta dalam hal meningkatkan status gizi pada ibu hamil.

Pada variabel riwayat kelahiran prematur menunjukan hasil uji chisquare didapat $p$-value $=0,004(\mathrm{p}<0,005)$ dan $\mathrm{OR}=2,7(95 \% \mathrm{CI}: 1,35-5,54)$ yang artinya secara statistik ada hubungan yang bermakna antara riwayat kelahiran prematur dengan kejadian kelahiran prematur dan Ibu yang memiliki riwayat kelahiran prematur berpeluang 2,7 kali untuk mengalami kelahiran prematur kembali. Menurut teori bahwa persentase kemungkinan kelahiran prematur berulang pada ibu hamil yang pernah mengalami kelahiran prematur 2 kali mempunyai risiko $32 \%$ untuk mengalami kelahiran prematur (Cunningham FG, 2014)

Hal ini sejalan dengan penelitian yang dilakukan oleh (Do Carmo Leal et al., 2016) di Brazil menunjukan $\mathrm{OR}=3,74$ (95\% CI: 2,92-4,79) bahwa faktor risiko riwayat kelahiran prematur berisiko 3,74 kali dalam kelahiran prematur. Menurut peneliti bahwa ibu hamil yang memiliki riwayat kelahiran prematur memiliki kecenderungan untuk terjadinya kelahiran prematur kembali maka sangat penting untuk mencegah dan mengobati infeksi intrauterine secara tuntas pada ibu hamil agar kehamilan dan persalinan mencapai cukup bulan.

Analisis statistic pada variabel merokok menunjukan hasil uji chi square $p$-value $=1,000 \quad(\mathrm{p}>=0,05)$ dan OR sebesar $0,9(0,16-5,03)$ yang artinya secara statistik tidak ada hubungan yang bermakna antara merokok dengan kelahiran prematur. Menurut teori bahwa Ibu hamil yang merokok dapat mengalami gangguan pertumbuhan selama kehamilan seperti abortus, BBLR, pre eklampsia, abruption placenta, dsb. Hal ini terjadi dikarenakan kandungan nikotin, tar dalam asap rokok merupakan radikal bebas yang akan merusak komponen molekul utama sel tubuh dan dapat menggganggu integritas sel, berkurangnya integritas sel membrane (Muntoha, Suhartno, 2013). Hasil penelitian ini tidak sejalan dengan penelitian (Smith et al., 2015) menunjukan $\mathrm{OR}=1,38$ (95\% CI: 1,041,84) bahwa wanita yang merokok selama kehamilan akan berpeluang 1,38 kali lebih tinggi untuk terjadinya kelahiran prematur dibandingkan yang tidak merokok. Hasil penelitian ini sejalan dengan hasil analisis statistic yang dilakukan (C. Prunet, 2016) dengan study retrospective di Prancis 
didapatkan $p$-value $=0,56$ dan $\mathrm{aOR}=1,0$ $(0,8-1,2)$. Peneliti berasumsi dari fakta yang ada bahwa budaya timur membuat ibu hamil tidak banyak memiliki kebiasaan merokok dan juga seiring pengetahuan ibu tentang bahaya asap rokok yang menimbulkan komplikasi selama kehamilan. Hal ini didukung dengan data yang didapatkan di lapangan penelitian sangat minim pada variabel merokok sehingga berpengaruh terhadap hasil analisa data secara statistik.

Pada variabel pemeriksaan ANC menunjukan Hasil uji chi square $p$ value $=0,031 \quad(\mathrm{p}<=0,05)$ artinya secara statistik ada hubungan yang bermakna antara pemeriksaan ANC dengan kelahiran prematur dan $\mathrm{OR}=2,5(95 \%$ CI: $1,15-5,71)$ artinya ibu hamil dengan ANC tidak standar memiliki risiko 2,5 kali lebih tinggi untuk mengalami kelahiran prematur. Hal ini sejalan dengan penelitian (Legawati et al., 2017) dengan hasil nilai OR sebesar 6,29 (95\% CI: 2,69-14,7). Pemeriksaan kehamilan merupakan pemeriksaan yang diberikan kepada ibu hamil oleh tenaga kesehatan selama kehamilannya dengan jumlah standar pemeriksaan minimal 4 kali. Pemeriksaan kehamilan diperlukan untuk memungkinkan diketahuinya secara dini kelainan atau pun masalah dalam kehamilan sehingga dapat diambil langkah yang tepat untuk menyelamatkan janin dan ibunya. Pelayanan antenatal terintegrasi merupakan pelayanan kesehatan komprehensif dan berkualitas sesuai standar (10T) (Depkes RI, 2015). Peneliti berasumsi bahwa pemeriksaan antenatal care (ANC) yang tidak standar jumlah kunjungannya menyebabkan tidak diketahuinya secara dini komplikasi kehamilan yang diderita ibu sehingga intervensi baik itu pencegahan ataupun penatalaksanaan dari komplikasi kehamilan tersebut tidak cepat teratasi. Sedangkan pada ibu yang memeriksakan kehamilan standar pun masih bisa mengalami kelahiran prematur jika pemeriksaan antenatal care (ANC) yang diberikan oleh tenaga kesehatan tidak sesuai standar kualitasnya yaitu 10T ataupun konseling yang kurang dipahami oleh ibu hamil maka sangat dianjurkan untuk meningkatkan kompetensi bagi tenaga kesehatan dalam memberikan pelayanan pemeriksaan ANC baik itu secara standar prosedur pelayanan ataupun dalam memberikan KIE sehingga ibu dapat melahirkan anak yang sehat pada usia kehamilan yang ideal yaitu 9 bulan. 


\section{SIMPULAN}

Dari hasil penelitian dapat disimpulkan bahwa hubungan yang signifikan antara usia ibu, pendidikan, riwayat kelahiran prematur, pemeriksaan ANC dengan kejadian kelahiran prematur sedangkan untuk variabel merokok tidak ada hubungan yang signifikan terhadap kelahiran prematur. Variabel yang paling dominan mempengaruhi kelahiran prematur adalah usia dan riwayat kelahiran prematur sebelumnya.

\section{DAFTAR PUSTAKA}

Blencowe, H., Cousens, S., Chou, D., Oestergaard, M., Say, L., Moller, A., \& Kinney, M. (2013). <Blencowe reprod health 2013.pdf>. Born Too Soon the Global Epidemiology of 15 Million Preterm Births, 10(Suppl 1), 1-14. https://doi.org/10.1186/17424755-10-S1-S2

C. Prunet, M. D.-C. (2016). Risk factors of preterm birth in France in 2010 and changes since 1995: Result from the French National Perinatal Surveys. Elsevier, http://dx.doi.org/10.1016/jjgyn.2016.02.010.

Cunningham FG, L. K. (2014). Obstetri Williams (Edisi 23). Jakarta:EGC

Halimah Rosyidah1, R. V. (2019). RELATIONSHIP BETWEEN THE AGE OF PREGNANT WOMEN AND PREMATURE LABOR IN PANEMBAHAN
SENOPATI REGIONAL PUBLIC HOSPITAL, BANTUL, YOGYAKARTA. BMJ. Vol 6 No 1, 2019: 14-23 ISSN : 2615-7047, 2615-7047.

Saifon Chawanpaiboon*, J. P.-B. (2019). Global, regional, and national estimates of levels of preterm.

http://dx.doi.org/10.1016/:S2214 -109X(18)30451-0. (n.d.).The Lancet Global Health.com/lancetgh Vol 7 January 2019. e37-46.

Depkes RI. (2015). Profil Kesehatan Indonesia. Jakarta: Departemen Kesehatan.

Dinkes Provinsi Sumsel. (2019). Laporan Kinerja Kesehatan Keluarga dan Gizi Masyarakat (D. K. profinsi S. S. Profil (ed.)). Do Carmo Leal, M., Esteves-Pereira, A. P., Nakamura-Pereira, M., Torres, J. A., Theme-Filha, M., Domingues, R. M. S. M., Dias, M. A. B., Moreira, M. E., \& Gama, S. G. (2016). Prevalence and risk factors related to preterm birth in Brazil. Reproductive Health, 13(Suppl $3)$.

https://doi.org/10.1186/s12978$\underline{016-0230-0}$

El-Sayed, A. M., \& Galea, S. (2012). Temporal changes in socioeconomic influences on health: Maternal education and preterm birth. American Journal of Public Health, 102(9), 17151721.

https://doi.org/10.2105/AJPH.20 $\underline{11.300564}$ 
Kemenkes. (2020). Pokok-Pokok Renstra Kemenkes 2020-2024. Pokja Renstra Kemenkes 20202024, 1-40.

$\begin{array}{cc}\text { Kesmas, D. (2020). } & \text { PEDOMAN } \\ \text { PENJELASAN } & \text { INDIKATOR } \\ \text { PROGRAM } & \text { KESEHATAN } \\ \text { KESEHATAN } & \text { TAHUN 2020- } \\ 2024 & \text { DIREKTORAT } \\ \text { JENDERAL } & \text { KESEHATAN } \\ \text { MASYARAKAT } & \text { TAHUN 2020. } \\ \text { 1-99. } & \end{array}$

Krisnadi SR, dkk. (2011). Panduan Pengelolaan Persalinan Preterm Nasional. Bandung: Himpunan Kedokteran Fetomaternal POGI.

Legawati, L., Riyanti, R., \& Noordiati, N. (2017). Faktor Maternal Dan Pelayanan Ante Natal Care Terintegrasi Pada Kejadian Prematuritas Di Puskesmas Wilayah Kota Palangka Raya. Jurnal Surya Medika, 3(1), 718.

https://doi.org/10.33084/jsm.v3i 1.209.

Marisa Ip, E. P. (2010). A case-control study of preterm delivery risk factors according to clinical subtypes and severityjog_1087 34..44. The Journal of Obstetries and Gynaecology Research, doi:10.1111/j.14470756.2009.01087.x.

Muntoha, Suhartno, N. endah w. (2013). Hubungan antara Riwayat Paparan Asap Rokok dengan Kejadian Ketuban Pecah Dini pada Ibu Hamil di RSUD Dr. H. Soewondo Kendal. Jurnal Kesehatan Lingkungan Indonesia, $\quad 12(1), \quad$ 88-93. https://doi.org/10.14710/jkli.12. $\underline{1.88-93}$

Profil RSU YK Madira, P. (2019). Laporan Rekam Medis Rumah Sakit Umum (RSU) YK MADIRA Palembang.

Smith, L. K., Draper, E. S., Evans, T. A., Field, D. J., Johnson, S. J., Manktelow, B. N., Seaton, S. E., Marlow, N., Petrou, S., \& Boyle, E. M. (2015). Associations between late and moderately preterm birth and smoking, alcohol, drug use and diet: A population-based case-cohort study. Archives of Disease in Childhood: Fetal and Neonatal Edition, 100(6), F486-F491. https://doi.org/10.1136/archdisc hild-2014-307265

Sulistiarini, D., \& Berliana, M. (2016). Faktor-Faktor yang Mempengaruhi Kelahiran Prematur di Indonesia: Analisis Data Riskesdas 2013. In $E$ Journal WIDYA Kesehatan Dan Lingkungan (Vol. 1, Issue 2).

Syarif, A. B., Santoso, S., \& Widyasih, H. (2017). Usia Ibu dan Kejadian Persalinan Preterm. Jurnal Kesehatan Ibu Dan Anak, 11(2), 20-24. https://doi.org/10.29238/kia.v11i $\underline{2.35}$

Wahyuni, R., dan Rohani, S. (2017). Faktor-faktor yang mempengaruhi persalinan preterm. Jurnal Aisyah Vol. 2 No. 1.

https://doi.org/10.30604/jika.v2i 1.33 . 
Zhang, Y., Liu, X., Gao, S., Wang, J., Gu, Y., Zhang, J., Zhou, X., \& Li, Q. (2012). Risk Factors for Preterm Birth in Five Maternal and Child Health Hospitals in Beijing.7(12),1-7.

https://doi.org/10.1371/journal.p one. 0052780 